\title{
Fotopedologia, espectroscopia e sistema de informação geográfica na caracterização de solos desenvolvidos do Grupo Barreiras no Amapá
}

\author{
José Alexandre Melo Demattê $\left({ }^{(*)}\right)$; Gustavo de Mattos Vasques ( $\left.{ }^{2}\right)$; Edvânia Aparecida Corrêa (3); \\ Gustavo Pais de Arruda (') \\ (') Universidade de São Paulo, Escola Superior de Agricultura "Luiz de Queiroz”, Departamento de Ciência do Solo, Caixa Postal 9, \\ 13418-900 Piracicaba (SP), Brasil. \\ (2) Embrapa Solos, Rua Jardim Botânico, 1024, Jardim Botânico, 22460-000 Rio de Janeiro (RJ), Brasil. \\ (3) Universidade Estadual Paulista, Departamento de Planejamento Territorial e Geoprocessamento, Av. 24 A, 1515, Bela Vista, \\ 13506-900 Rio Claro (SP), Brasil. \\ (*) Autor correspondente: jamdemat@usp.br
}

Recebido: 20/jul./2012; Aceito: 5/set./2012

\section{Resumo}

O presente trabalho utilizou ferramentas de sensoriamento remoto e sistema de informação geográfica, aliadas às informações espectrais do solo e quantitativas e qualitativas do relevo, para a caracterização e discriminação das classes de solos desenvolvidos do Grupo Barreiras na região do município de Porto Grande, Amapá. Após o mapeamento semidetaIhado de solos, realizou-se a caracterização pontual das amostras dos perfis por meio de espectroscopia de visível e infravermelho (400-2500 nm), e a análise espacial das redes de drenagem e relevo a partir de fotos aéreas e imagens de radar. As informações quantitativas do relevo foram mais eficientes na caracterização e discriminação dos solos estudados do que as qualitativas, enquanto as informações espectrais permitiram caracterizar os solos em nível pontual. Métodos espaciais utilizando redes de drenagem e relevo e métodos espectrais utilizando amostras pontuais complementam-se na caracterização e discriminação de solos na paisagem.

Palavras-chave: fotografia aérea, espectroscopia de visível e infravermelho, classificação de solos, geomorfologia.

\section{Photopedology, spectroscopy, and GIS to characterize soils developed over the Barreiras Group in Amapá, Brazil}

\section{Abstract}

This study applied remote sensing and geographic information system tools, along with soil spectral data and quantitative and qualitative relief information, to characterize and separate soil classes developed over the Barreiras Group in the region of Porto Grande, state of Amapá, Brazil. After mapping soils at the semi-detailed level, soil samples from individual profiles were characterized using visible and infrared (400-2500 nm) spectroscopy, and the drainage system and relief were analyzed spatially based on aerial photographs and radar imagery. Quantitative relief information was more efficient than qualitative ones to characterize and separate soils, whereas the soil spectral data allowed the characterization of soil profiles individually. The spatial assessment of the drainage system and relief, and the spectral assessment of individual soil profiles are complementary to characterize and separate soils on the landscape.

Key words: aerial photography, visible and infrared spectroscopy, soil classification, geomorphology. 


\section{INTRODUÇÃO}

No período em que eram realizados os grandes levantamentos de solos — décadas de 1960 a 1980 - a fotointerpretação era frequentemente utilizada como técnica de auxílio para o levantamento (RANZANi, 1969) e caracterização dos solos, originando inclusive o termo fotopedologia (França e Demattê, 1990). Em meados da década de 1980, entretanto, as fotografias aéreas começaram a ser gradativamente substituídas em decorrência da adoçáo de novas tecnologias em levantamento de solos, incluindo o Sistema de Posicionamento Global (GPS), mapeamento digital de solos e a ampla disponibilidade de imagens de satélite. Esse rompimento do uso em grande escala da fotopedologia como base para o mapeamento de solos gerou uma lacuna no levantamento de solos, bem como nesse tipo de pesquisa no Brasil. Portanto, há necessidade de retomada de estudos utilizando fotografias aéreas, relevo e geomorfologia como base para o mapeamento de solos.

Apesar das fotografias aéreas não detectarem características da camada subsuperficial do solo, em muitos trabalhos foram utilizadas para o entendimento contextual da distribuição espacial de solos. Fotografias aéreas representam ou facilitam a obtenção de elementos importantes para entender a formação dos solos, como o relevo e a posição do solo na paisagem, permitindo seu mapeamento e caracterização. Para auxiliar no levantamento de solos, novas técnicas estão sendo testadas e integradas, entre as quais a espectroscopia tem ganhado campo e respaldo na ciência do solo ao oferecer uma opção eficiente para a coleta, preparo e análise de solos, com resultados promissores (Demattê et al., 2004; Madeira Netto, 1996). A espectroscopia baseia-se no fato de que a energia eletromagnética incidente no solo interage com vários de seus componentes, sendo refletida nos diferentes comprimentos de onda em função dessas interaçôes. Por esse motivo, a chamada curva de reflectância espectral é única para cada amostra de solo.

O desenvolvimento de uma região depende de estudos básicos, incluindo a caracterizaçáo de solos. O Estado do Amapá tem extensa área de solos provenientes do Grupo Barreiras. Os solos desse Grupo possuem variaçóes pedogenéticas diferenciadas devido à desestabilizaçăo dos óxidos de ferro, causando a formação de materiais sedimentares e lateríticos em diversas etapas de desenvolvimento. Esses solos têm sido estudados sob o aspecto geológico, mas pouco sob o aspecto de relevo, ainda mais em conjunto com suas propriedades espectroscópicas. Assim, o presente trabalho tem como objetivo caracterizar os solos desenvolvidos do Grupo Barreiras por meio dos seus aspectos de relevo, associados às informações espectroscópicas. Espera-se que as características dos solos relacionadas aos óxidos de ferro possam ser discriminadas em função do relevo e da informação espectral.

\section{MATERIAL E MÉTODOS}

\section{Caracterização da área de estudo}

A área de estudo localiza-se na regiáo do município de Porto Grande, Amapá, entre as latitudes $0^{\circ} 00^{\prime}$ e $4^{\circ} 00^{\prime}$ Norte e longitudes $49^{\circ} 30^{\prime}$ e $54^{\circ} 00^{\prime}$ Oeste, e possui uma área de aproximadamente 25.000 ha. A região apresenta uma precipitaçáo pluvial média anual em torno de $2.200 \mathrm{~mm}$, com os meses mais chuvosos de janeiro a julho, e temperatura média anual de $29^{\circ} \mathrm{C}$. Geologicamente, a área é bastante homogênea, sendo o Grupo Barreiras a que mais contribui com material sedimentar, de textura variável, associado com material laterítico na forma de lajes ou em concreções de diversos tamanhos. O material do Grupo Barreiras dá origem a diversos solos, como Latossolos Amarelos de textura variável, Argissolos Amarelos, Neossolos Quartzarênicos e Plintossolos, que constituem os objetos de estudo do presente trabalho.

\section{Levantamento de solos e análises de laboratório}

O levantamento de solos em nível semidetalhado foi realizado seguindo o método de EMBRAPA (1995), sendo os solos classificados de acordo com EMBRAPA (2006). A simbologia utilizada foi baseada em EMBRAPA (2006), A simbologia utilizada foi baseada em EMBRAPA (2006) até o nível categórico de subordem, sendo acrescidos três números. São acrescidos três números: o primeiro indica a classe textural, o segundo a condição química e o terceiro o nível de concreçôes. Essa simbologia adapta-se às condiçóes de solos encontradas na área de estudo e está exemplificada na tabela 1 .

Como base para o mapeamento, foi utilizada uma imagem de radar na escala de 1:25.000 (RADAM, 1974). Foram realizadas 277 tradagens, com coleta de amostras nas profundidades de $0-20$ e $80-100 \mathrm{~cm}$, e abertos 25 perfis nas áreas mais representativas. Em cada ponto amostral realizou-se o georreferenciamento, a descrição do perfil (SANTOs et al., 2005), análises química (RAIj et al., 1987), granulométrica e mineralógica (CAmargo et al., 1986), e a leitura quantitativa da cor utilizando o colorímetro CR300 (Konica Minolta Sensing Americas, Inc., Ramsey, NJ, EUA) conforme Campos e Demattê (2004).

\section{Caracterização da rede de drenagem e índices de relevo}

Inicialmente, uma primeira aproximação dos canais de drenagem foi traçada com base na imagem de radar 
Tabela 1. Resultados analíticos de alguns perfis representativos dos solos da área de estudo

\begin{tabular}{|c|c|c|c|c|c|c|c|c|c|c|c|}
\hline \multirow{3}{*}{ Solo (1) } & \multicolumn{11}{|c|}{ Atributos (2) } \\
\hline & Profundidade & M.O. & CTC & V & m & Areia & Silte & Argila & Cor úmida & $\mathrm{Fe}_{2} \mathrm{O}_{3}$ & $\mathbf{K i}$ \\
\hline & $(\mathrm{cm})$ & $\left(\mathrm{g} \mathrm{kg}^{-1}\right)$ & $\begin{array}{c}\left(\mathrm{cmol}{ }_{\mathrm{c}}\right. \\
\left.\mathrm{kg}^{-1}\right)\end{array}$ & & & & $\left(\mathrm{g} \mathrm{kg}^{-1}\right)$ & & Munsell & $\left(\mathrm{g} \mathrm{kg}^{-1}\right)$ & \\
\hline \multirow[t]{3}{*}{ FFc } & $0-15$ & 35 & 6,74 & 5 & 78 & 600 & 80 & 320 & 9,2 YR 4,1/1,9 & & \\
\hline & $15-50$ & 9 & 2,01 & 10 & 49 & 450 & 70 & 480 & 8,3 YR $4,7 / 3,3$ & 10,26 & 1,59 \\
\hline & $50-160$ & 6 & 2,21 & 10 & 59 & 310 & 60 & 630 & 2,7 YR $4,4 / 3,3$ & & \\
\hline \multirow[t]{3}{*}{ LA 2-5 } & $0-18$ & 20 & 4,49 & 24 & 42 & 760 & 40 & 200 & 0,1 Y 4,1/1,7 & & \\
\hline & $18-60$ & 9 & 2,21 & 10 & 59 & 720 & 40 & 240 & 9,8 YR 4,9/3,7 & 2,21 & 1,49 \\
\hline & $60-150$ & 7 & 2,01 & 10 & 49 & 680 & 40 & 280 & 9,8 YR 4,9/3,6 & 2,28 & 1,01 \\
\hline \multirow[t]{3}{*}{ LA 1-5 } & $0-18$ & 35 & 9,09 & 3 & 85 & 410 & 40 & 550 & 0,1 Y 3,9/1,5 & & \\
\hline & $18-80$ & 12 & 2,21 & 10 & 49 & 390 & 40 & 570 & 7,9 YR 4,7/3,5 & 5,33 & 1,42 \\
\hline & $80-150$ & 7 & 2,01 & 10 & 32 & 260 & 80 & 600 & 6,9 YR 4,9/4,1 & & \\
\hline \multirow[t]{4}{*}{ LA 2-5-2 } & $0-12$ & 18 & 4,48 & 15 & 60 & 700 & 20 & 280 & 9,1 YR $4,1 / 2,3$ & & \\
\hline & $12-55$ & 10 & 2,95 & 15 & 53 & 640 & 60 & 300 & 8,3 YR 4,7/3,4 & 3,58 & 1,17 \\
\hline & $55-85$ & 7 & 2,23 & 10 & 57 & 620 & 40 & 340 & 7,0 YR $4,7 / 3,4$ & 5,01 & 1,73 \\
\hline & $85-150$ & 7 & 2,34 & 15 & 37 & 640 & 60 & 300 & 6,3 YR 4,4/3,0 & & \\
\hline \multirow[t]{3}{*}{ LA 2-5-3 } & $0-12$ & 16 & 4,68 & 10 & 71 & 700 & 60 & 240 & 9,6 YR 4,0/1,8 & & \\
\hline & $12-110$ & 7 & 2,22 & 10 & 69 & 680 & 20 & 300 & 8,1 YR 5,3/4,2 & 2,31 & 1,63 \\
\hline & $110+$ & 7 & 2,54 & 13 & 54 & 580 & 20 & 400 & 6,3 YR 5,0/4,2 & & \\
\hline \multirow[t]{2}{*}{ FFlp } & $0-10$ & 20 & 3,35 & 7 & 76 & 590 & 80 & 330 & 9,7 YR 4,3/2,4 & & \\
\hline & $10-60$ & 7 & 2,41 & 9 & 66 & 580 & 40 & 380 & 8,0 YR $4,4 / 2,6$ & 12,05 & 1,63 \\
\hline \multirow[t]{3}{*}{ PA 1-5-1 PL } & $0-21$ & 14 & 3,15 & 11 & 59 & 640 & 120 & 240 & 7,3 YR 3,7/1,3 & & \\
\hline & $21-60$ & 7 & 2,43 & 9 & 57 & 360 & 60 & 580 & 9,0 YR $4,8 / 3,1$ & 6,42 & 1,78 \\
\hline & $60-150$ & 4 & 2,64 & 17 & 61 & 150 & 20 & 830 & 2,7 YR $4,4 / 2,8$ & 4,86 & 1,94 \\
\hline \multirow[t]{4}{*}{ CX 13} & $0-12$ & 20 & 4,04 & 6 & 81 & 450 & 40 & 510 & 0,1 Y 4,6/2,5 & & \\
\hline & $12-50$ & 8 & 2,72 & 8 & 69 & 400 & 40 & 560 & 9,2 YR 4,9/3,2 & 4,86 & 1,68 \\
\hline & $50-100$ & 7 & 2,44 & 10 & 56 & 420 & 40 & 540 & 8,0 YR $4,8 / 3,4$ & & \\
\hline & $100-150$ & 5 & 2,44 & 10 & 68 & 350 & 40 & 610 & 4,1 YR 4,8/3,5 & & \\
\hline \multirow[t]{3}{*}{ RQ 4-5-HI } & $0-20$ & 19 & 3,87 & 12 & 60 & 900 & 40 & 60 & 8,4 YR $4,1 / 1,0$ & & \\
\hline & $20-80$ & 10 & 1,31 & 16 & 49 & 920 & 60 & 20 & 6,6 YR 4,3/1,9 & 0,21 & 8,23 \\
\hline & $80-150$ & 9 & 1,71 & 12 & 49 & 960 & 20 & 20 & 7,3 YR $4,3 / 1,7$ & & \\
\hline \multirow[t]{2}{*}{ FFc } & $0-10$ & 24 & 5,92 & 12 & 63 & 700 & 40 & 260 & 9,4 YR 4,1/2,0 & 8,90 & 1,30 \\
\hline & $10-50$ & 10 & 2,42 & 9 & 48 & 640 & 40 & 320 & 8,0 YR $4,4 / 3,2$ & & \\
\hline
\end{tabular}

(1) FFc: Plintossolo Pétrico concrecionário; LA 2-5: Latossolo Amarelo distrófico textura média-argilosa; LA 1-5: Latossolo Amarelo distrófico textura argilosa; LA 2-5-2: Latossolo Amarelo distrófico textura média-argilosa endoconcrecionário; LA 2-5-3: Latossolo Amarelo distrófico textura média-argilosa concrecionário; FFlp: Plintossolo Pétrico litoplíntico; PA 1-5-1 PL: Argissolo Amarelo distrófico textura argilosa epiconcrecionário com plintita; CX 13: Cambissolo Háplico textura indiscriminada; RQ 4-5-HI: Neossolo Quartzarênico distrófico com hidromorfismo. $\left(^{2}\right)$ M.O.: matéria orgânica; CTC: capacidade de troca catiônica; $\mathrm{V}$ : saturaçấo por bases; m: saturação por alumínio; $\mathrm{Ki}_{1}$ 1,7*SiO${ }_{2} / \mathrm{Al}_{2} \mathrm{O}_{3}$.

(1:25.000). Essa primeira aproximação foi refinada utilizando-se fotografias aéreas na escala de 1:60.000, observadas em estereoscópio de espelhos. As informaçōes do mapa de solos, perfis e tradagens georreferenciados, rede de drenagem, imagem de radar e fotografias aéreas foram inseridas em um sistema de informação geográfica através do programa ArcGIS (Environmental Systems Research Institute, Redlands, CA, EUA). Com base nesses dados, foram alocadas 15 amostras circulares com raio de $1 \mathrm{~km}$ nas áreas representativas das unidades de solos. Para cada amostra circular, foi realizada a análise descritiva da rede de drenagem segundo Lueder (1959). Além disso, calculou-se a porcentagem de ocorrência de cada solo dentro da amostra circular, a densidade de drenagem (DD) (França e Demattê, 1990), a elevação e a declividade.

\section{Aquisição e avaliação dos dados espectrais}

As amostras de terra de cada horizonte foram secas $\left(45^{\circ} \mathrm{C}\right.$ por 24 horas), moídas e peneiradas $(2 \mathrm{~mm})$. A leitura das curvas espectrais das amostras de terra na regiáo do visível e infravermelho foi feita no espectrorradiômetro IRIS (Infrared Intelligent Spectroradiometer) Mark V (Geophysical \& Environmental Research Corporation, Millbrook, NY, EUA), com resolução de $1 \mathrm{~nm}$ na faixa de 400 a $1000 \mathrm{~nm}$ e $2 \mathrm{~nm}$ na faixa de 1000 a $2500 \mathrm{~nm}$. Em detalhe, placas de petri de $10 \mathrm{~cm}$ de diâmetro foram preenchidas com amostras até completar $1 \mathrm{~cm}$ de profundidade, e a superfície aplainada. Uma lâmpada halógena de $50 \mathrm{~W}$ foi posicionada a $61 \mathrm{~cm}$ da amostra de terra em ângulo zenital de $15^{\circ}$ e o espectrorradiômetro posicionado verticalmente sobre a amostra a uma distância de $27 \mathrm{~cm}$. 
Utilizou-se placa-padrão cinza com 50\% de reflectância, sendo a curva obtida transformada para $100 \%$ de fator de reflectância bidirecional (Demattê e Garcia, 1999).

As curvas espectrais foram avaliadas descritivamente em função da intensidade de reflectância, bandas de absorção e forma geral da curva, de acordo com Demattê (2002).

\section{RESULTADOS E DISCUSSÃO}

\section{Caracterização dos solos e posição na paisagem}

O Grupo Barreiras é originário principalmente de sedimentação fluvial ocorrida na era Cenozóica, período Terciário, sendo constituída principalmente por arenito ferruginoso, argilito, siltito, caulim e bauxito. As litologias deste Grupo são variadas, com gama de tons, predominando os tons avermelhados, amarelados e esbranquiçados. Em geral, as rochas são mal consolidadas argilosas, siltosas e arenosas e, por vezes, com níveis e leitos mais grosseiros (RADAM, 1974). O Grupo Barreiras se expressa morfologicamente como platôs baixos e dissecados ou como relevo colinoso, com rede de drenagem bastante densa e ramificações de canais de cabeceira, que sugerem uma retomada de erosão recente. São observáveis também alguns vales com fundo plano, assoreados por depósitos aluviais.

É bastante comum a ocorrência das chamadas lateritas no Grupo Barreiras. Estas constituem um material duro formado por intemperismo muito agressivo das rochas da região, representado por concreções de óxidos principalmente de ferro e alumínio. $\mathrm{Na}$ região de estudo, há extensas áreas recobertas por lateritas, tanto na margem esquerda como na direita do rio Araguari e também mais ao sul em direção a Macapá. A disposição destas formaçôes é no sentido norte-sul, principalmente em encostas ou nas áreas planas quando o relevo apresenta ondulaçóes na forma de pequenos morros testemunhos associados com material plíntico, os quais são comuns na área de estudo.

As lateritas presentes na região são consolidadas (na forma de bancadas e lajes de grande espessura) ou não consolidadas (na forma pedregosa, de tamanho e espessura variados). O relevo da regiāo é predominantemente suave ondulado a ondulado e, em alguns trechos, forte ondulado. Nas áreas mais planas da região é comum a ocorrência de pequenas depressôes de drenagem lenta, onde tipicamente formam-se Gleissolos (Figura 1a). Em áreas planas, tipicamente ocorrem Latossolos Amarelos e, em quebras pequenas de relevo, Plintossolos Pétricos.

As classes de solos da área de estudo relacionam-se com os diferentes níveis de endurecimento e de concreçôes do material ferruginoso. Assim, pode haver solos que contêm camadas concrecionárias e lateríticas tanto em situação não diagnóstica como diagnóstica. No primeiro caso, foram detectados os materiais concrecionários em perfis que caracterizaram Latossolos, tendo-se então os Latossolos concrecionários. No segundo caso, foram observados os Plintossolos Pétricos concrecionários e litoplínticos.

Para o caso específico dos Latossolos, observou-se a presença de nódulos de concreçôes em diferentes posiçóes do perfil, cabendo as designaçóes concrecionário, endoconcrecionário e epiconcrecionário respectivamente. Em termos morfológicos, os Latossolos concrecionários são caracterizados por terem em todos os horizontes concreçôes ou nódulos lateríticos de tamanho variado, porém volume não superior a $50 \%$, e solo e microagregrados em todo o perfil por entre este material. Não foi possível determinar a estrutura, pois ela se integra ao solo de maneira solta. Apesar do volume de concreçôes, a presença do material latossólico é predominante, permitindo inclusive o cultivo do eucalipto na região. Em outra situação, o perfil mostra o material latossólico predominantemente na parte superficial indo até $1,2 \mathrm{~m}$, surgindo depois material laterítico não consolidado (nódulos e concreçôes), sendo classificado como Latossolo endoconcrecionário. Em uma terceira situação bastante típica na regiấo, a camada de concreçôes lateríticas ocorre na superfície, indo até a faixa dos $50 \mathrm{a} 60 \mathrm{~cm}$, após a qual ocorre material latossólico típico até o fim do perfil, o qual é então denominado de Latossolo endoconcrecionário. A figura 1 ilustra estas situaçóes. De maneira geral, excetuando-se as peculiaridades dos níveis de concreçôes, as classes de solos da regiáo são bastante similares das de outras regiốes e são a seguir descritas.

Os Latossolos Amarelos são um dos principais solos de ocorrência na região. São profundos $(>200 \mathrm{~cm})$, bem drenados e ocorrem principalmente em relevo plano a suave ondulado, porém foram também observados em relevo mais movimentado nesta regiāo. $\mathrm{Na}$ faixa dos 20 a $30 \mathrm{~cm}$ de profundidade há pequenas pontuaçóes de cor acinzentada indicando encharcamento temporário, principalmente para as unidades de textura média-argilosa a argilosa. Tal encharcamento é devido ao bloqueamento de poros pela translocação de argila, típicos em solos oriundos deste Grupo. As cores nos horizontes inferiores são mais amareladas do que $5 \mathrm{YR}$, normalmente com matizes $10 \mathrm{YR}$, e teores de argila variando de 150 a $600 \mathrm{~g} \mathrm{~kg}^{-1}$ e distróficos em sua maioria (Tabela 1). Alguns desses solos são observados nas superfícies dissecadas em colinas de topo aplainado e em áreas aplainadas com drenagem pouco entalhada, sendo comum a presença de cascalho. Estes solos contêm evidência de um estágio avançado de intemperismo, com horizonte de subsuperfície alterado, consistindo em uma mistura de óxidos hidratados de ferro e alumínio com variável proporção de argila 1:1, quartzo e minerais acessórios. Devido à ação de diversos ciclos erosivos, a massa de solo amarelo está misturada com fragmentos (concreçóes) de diversos tamanhos de material laterítico.

Os Argissolos Amarelos ocorrentes na área de estudo também contêm fragmentos de material laterítico, porém 
(b)

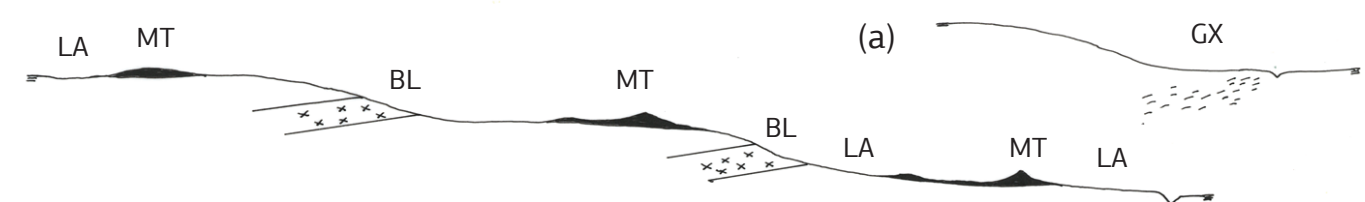

(c)

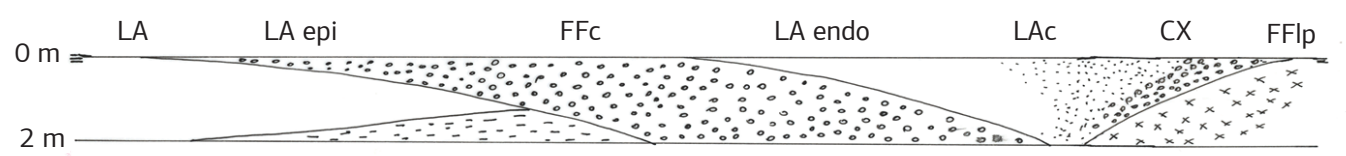

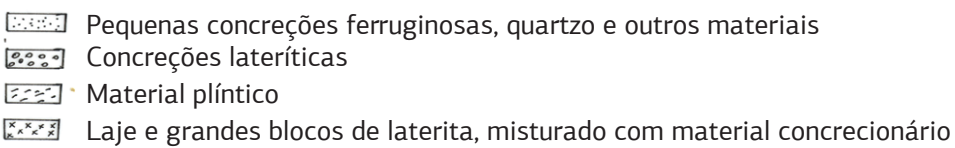

Figura 1. Esquema ilustrativo da distribuição dos solos e materiais concrecionários na área de estudo, sendo: (a) topossequência mostrando os locais de ocorrência de Latossolo Amarelo (LA) e Gleissolo Háplico (GX); (b) topossequência indicando a ocorrência de morros testemunho (MT) e bancadas lateríticas (BL); e (c) pedolitossequência típica da área de estudo, indicando a ocorrência de LA, LA epiconcrecionário (LAepi), Plintossolo Pétrico concrecionário ( $\mathrm{FFc}$ ), LA endoconcrecionário (LAendo), LA concrecionário (LAc), Cambissolo Háplico (CX) e Plintossolo Pétrico litoplíntico (FFlp), bem como a profundidade aproximada de ocorrência dos materiais concrecionários.

diferem dos Latossolos por serem menos profundos (entre 1,50 e $2,00 \mathrm{~m}$ ) e com gradiente textural mais acentuado (Tabela 1). Eles se localizam em relevo mais movimentado e, em geral, possuem a sequência de horizontes $\mathrm{Ap}, \mathrm{Bt}, \mathrm{C}$, sendo o horizonte A normalmente caracterizado como A fraco ou A moderado. A drenagem é boa na superfície, porém mais lenta na subsuperfície, podendo ter encharcamento temporário, principalmente nas camadas mais inferiores e, em certos casos, nas camadas superficiais. As cores nos horizontes inferiores estão na faixa de 10YR, podendo ocorrer manchas de cores de redução se a drenagem for mais impedida. São quimicamente pobres, com baixa saturação por bases, distróficos e com argila de baixa atividade. Nos perfis, podem ocorrer ou náo concreçóes lateríticas, como no caso dos Latossolos Amarelos. Em áreas onde não há ocorrência de Latossolos, os Argissolos ocupam as posiçóes mais elevadas do relevo, transitando à jusante para solos mais rasos, tais como Cambissolos ou Neossolos Litólicos.

Os Cambissolos possuem pouca profundidade (30 a $80 \mathrm{~cm}$ ), textura variável (de arenosa a argilosa) e drenagem geralmente lenta, com possibilidade de encharcamento temporário e, em relevo plano, podem ter drenagem impedida. Normalmente ocorrem em relevo ondulado a forte e, por serem rasos, possuem baixa retenção de água. Quimicamente, possuem argila de baixa atividade e são geralmente distróficos. A sequência de horizontes é normalmente $\mathrm{Ap}, \mathrm{Bi}, \mathrm{C}, \mathrm{R}$, sendo que $\mathrm{A}$ fraco ou $\mathrm{A}$ proeminente aparecem na superfície e $\mathrm{B}$ incipiente $(\mathrm{Bi})$ na subsuperfície.

Os Neossolos Quartzarênicos são solos arenosos, com teor de argila inferior a $15 \%$ dentro dos primeiros $1,5 \mathrm{~m}$ de profundidade, bem drenados, de ocorrência em relevo plano a suave ondulado. As cores são variáveis, de pardo a amarelado, porém com matiz de $7.5 \mathrm{YR}$ a $10 \mathrm{YR}$ no horizonte C. Nas depressóes e próximo às grotas ou córregos, as cores tendem a ficar mais esbranquiçadas devido à remoção do ferro pela água. Possuem capacidade de troca catiônica (CTC) na faixa de $2 \mathrm{cmol}_{\mathrm{c}} \mathrm{kg}^{-1}$, sendo na maioria distróficos.

Os Plintossolos Pétricos concrecionários são medianamente profundos, formados por uma mistura de partículas minerais finas e concreçôes de vários diâmetros que, na maioria dos casos, representam o maior volume do solo, impedindo ou dificultando o uso agrícola. Os perfis podem ter textura variável, com sequência de horizontes Ac, Bc e Cc, sendo c relativo a concreçôes e/ou cascalhos.

Os Plintossolos Pétricos litoplínticos possuem as exposiçôes de laterita mais típicas. Podem ocorrer em forma de pequenos morrotes isolados em uma área plana ou nas encostas. Estão associados a solos rasos e cascalhentos (por exemplo, Cambissolos) e com sérias limitaçôes ao uso agrícola. Os Plintossolos Pétricos litoplínticos diferenciam-se dos concrecionários pelo grau de dureza do material, sendo o primeiro com camada impermeável e o segundo com concreçôes intercaladas com material solo.

É muito comum nesta região o aparecimento de plintita em profundidade variável no solo. Como a formação da plintita envolve ambiente redutor, de drenagem lenta ou impedida, ela pode ocorrer em qualquer classe de solo, assim como, pelo mesmo motivo, as concreçóes ferruginosas. No campo, as transiçõos típicas entre solos não concrecionários e solos concrecionários eram determinadas por alteraçóes do relevo, ainda que pequenas, sendo que os primeiros dominavam as áreas planas e os últimos as áreas de quebra de relevo. Conforme o exposto, a regiáo apresenta em geral solos distróficos, de baixa CTC, cascalhentos e de textura variável. 


\section{Caracterização descritiva da rede de drenagem e relevo}

Apesar da pequena escala das fotografias aéreas (1:60.000), a rede de drenagem observada possibilitou a visualização do relevo altamente dissecado. A imagem de radar, apesar de não permitir interpretação tridimensional, possibilitou observar e delinear a rede de drenagem. Destaca-se que a região possui clima muito instável e chuvoso, sendo a imagem de radar, nesse caso, mais indicada do que as imagens obtidas por sensores passivos (por exemplo, aqueles sensíveis às faixas espectrais no visível e infravermelho), já que atravessa nuvens e é pouco influenciada pelas condições atmosféricas. Tal fato concorda com trabalhos de levantamento de solos do Projeto Radam para a região Amazônica (RADAM, 1974).

Dentre os principais tipos de rede de drenagem observados na área de estudo, destacam-se o subdendrítico e o dendrítico nas áreas de Plintossolo Pétrico concrecionário e o subparalelo nas áreas com predominância de Latossolo, com alto grau de integração, pouca orientação e ângulos de confluência retos ou tendendo a retos. O relevo predominante da área é do tipo normal, com infiltração maior do que deflúvio, suave ondulado e com gradiente suave. Nos locais com predominância de Plintossolo Pétrico litoplíntico e Cambissolo, as redes de drenagem são do tipo dendrítico, com alta densidade de canais, alto grau de integração, sem orientação e com ângulos de confluência retos ou agudos tendendo a retos. O relevo é do tipo excessivo, com deflúvio maior do que infiltração, montanhoso e com gradiente forte.

Não se tem notícia de trabalhos que tenham caracterizado solos oriundos do Grupo Barreiras no Estado do Amapá. Essa região mostra uma peculiaridade: os Plintossolos Pétricos litoplínticos ocorrem em rede de drenagem subdendrítica extremamente demarcada, sem anomalias, facilitando sua identificação pelas fotos aéreas. No campo, esses solos são também facilmente identificados pelo relevo mais ondulado e pela pouca profundidade e, em vários casos, a laterita está exposta. Observa-se, portanto, a ocorrência dos diferentes solos do Grupo Barreiras em conformaçôes de rede de drenagem distintas na paisagem.

\section{Caracterização quantitativa da rede de drenagem e relevo}

Os dados descritivos e quantitativos (elevação, declividade e DD), obtidos através de fotointerpretação e processamento de imagens, mostraram coerência entre si (Tabelas 2 e 3; Figura 2). Em geral, as amostras circulares com maior ocorrência de Latossolos tiveram baixa DD $\left(<1 \mathrm{~km} \mathrm{~km}^{-2}\right)$ e baixa declividade $(<2 \%)$ (valores médios). Já as amostras circulares com maior ocorrência de Plintossolo Pétrico concrecionário apresentaram maior
DD $\left(>2 \mathrm{~km} \mathrm{~km}^{-2}\right)$ e maior declividade (> 4\%). As amostras circulares menos puras, com ocorrência mais balanceada de Latossolos e Plintossolos, em geral, tiveram valores intermediários de DD (1 a $\left.2 \mathrm{~km} \mathrm{~km}^{-2}\right)$ e declividade (2\% a $3 \%)$. Esse fato mostra como o relevo e a rede de drenagem regulam os processos de infiltração e deflúvio, influindo na formação dos diferentes solos encontrados na região. A relação entre o padrão de drenagem e classes de solos é ilustrada na Figura 2.

Partindo da amostra circular 1 para a 9 e para a 15 , observa-se um ambiente com predominância de Latossolos, seguido de um ambiente com ocorrência mais equilibrada de diversos solos, até um ambiente em que predominam Plintossolos. Nesta sequência, a DD passa, coerentemente, de 0,87 para 1,80 e para 2,95 .

A presença de baixa DD nas áreas com ocorrência de Latossolos explica as características morfológicas desses solos, como alta permeabilidade, profundidade e porosidade. Nestas áreas (com rede de drenagem do tipo subparalelo), observam-se cursos d'água de forma mais retilínea e de menor comprimento, com DD menor em relação às áreas com rede de drenagem dendrítica, onde os cursos d'água são mais ramificados e com maior comprimento. Esse último é o caso das áreas de alta DD, que propiciam a formação de solos rasos, com baixa taxa de infiltração e alto valor de deflúvio, destacando-se os Cambissolos e Plintossolos.

\section{Caracterização espectral dos solos}

Nas curvas espectrais de alguns perfis selecionados (Figura 3), observa-se uma concavidade em torno de $900 \mathrm{~nm}$, indicativa da presença de concreçôes. Ela ocorre nas curvas espectrais do Latossolo Amarelo distrófico textura média-argilosa endoconcrecionário (Figura 3a), do Plintossolo Pétrico concrecionário (Figura 3b) e do Plintossolo Pétrico litoplíntico (Figura 3c). Por outro lado, na curva espectral do Neossolo Quartzarênico (Figura 3d), coerentemente, não há essa concavidade.

Os Neossolos Quartzarênicos da área de estudo (Figura 3d) são distintos daqueles observados no Sudeste do Brasil, por não haver feiçôes de absorçáo relativas aos óxidos (por exemplo, em torno de 430 e $830 \mathrm{~nm}$ ), o que indica sua ausência. A mineralogia desses solos é praticamente dominada pelo quartzo, conferindo uma curva quase horizontal e plana, sem feições típicas de outros materiais, concordando com DematTê (2002).

Outra feição de absorção característica de material concrecionário pode ser observada na curva espectral do Latossolo Amarelo distrófico textura média-argilosa endoconcrecionário (Figura 3a). Ela se caracteriza pela curvatura diferenciada na faixa em torno de 650 $\mathrm{nm}$, oriundas das concreçóes de ferro. A forma da curva como um todo difere de todas as formas observadas por Formaggio et al. (1996) e também não se 
Tabela 2. Classes de solo predominantes e valores de densidade de drenagem (DD) nas amostras circulares

\begin{tabular}{|c|c|c|c|c|}
\hline \multirow{2}{*}{ Amostra circular } & \multicolumn{3}{|c|}{ Classes de solo predominantes e percentual de ocupação ${ }^{(1)}$} & \multirow{2}{*}{$\begin{array}{c}\text { DD } \\
\left(\mathrm{km} \mathrm{km}^{-2}\right)\end{array}$} \\
\hline & & (\%) & & \\
\hline 1 & LA 3-5 $(97,3)$ & $\mathrm{FF}(2,7)$ & & 0,87 \\
\hline 2 & LA 2-5 $(81,4)$ & PA 2-5 PL $(8,0)$ & LA 3-5 $(6,5)$ & 0,24 \\
\hline 3 & LA 2-5 $(90,3)$ & $\mathrm{FF}(9,7)$ & & 0,72 \\
\hline 4 & LA 1-4 $(74,6)$ & LA 3-5 $(15,2)$ & LA $2-5-3(6,7)$ & 0,27 \\
\hline 5 & $\mathrm{FF}(100,0)$ & & & 1,52 \\
\hline 6 & $F F+F F c(63,5)$ & LA 1-5-2 $(21,6)$ & $\operatorname{FFc}(8,6)$ & 1,42 \\
\hline 7 & FF $(95,2)$ & LA $1-5-2(4,8)$ & & 3,73 \\
\hline 8 & FF $(74,8)$ & LA 1-5 $(16,7)$ & LA 1-5-2 (8,5) & 2,66 \\
\hline 9 & LA 1-5 $(35,4)$ & $\mathrm{FF}(33,1)$ & LA 1-6 $(31,5)$ & 1,80 \\
\hline 10 & $\mathrm{FF}(95,6)$ & LA 1-6 (2,9) & LA 1-5 $(1,0)$ & 1,80 \\
\hline 11 & LA 1-5 $(70,3)$ & LA 1-6 $(18,4)$ & $\mathrm{FF}(9,7)$ & 1,22 \\
\hline 12 & LA $1-5(47,3)$ & FF $(42,0)$ & CX $13(7,2)$ & 1,22 \\
\hline 13 & $\mathrm{FF}+\mathrm{FFc}(40,4)$ & LA 1-5 $(25,4)$ & $\mathrm{FF}(12,5)$ & 1,64 \\
\hline 14 & FF $(66,7)$ & $F F+F F c(13,8)$ & $F F+F F c+L A 1-5-2(8,7)$ & 2,47 \\
\hline 15 & $F F+F F c(100,0)$ & & & 2,95 \\
\hline
\end{tabular}

(1) LA 3-5: Latossolo Amarelo distrófico textura média-arenosa; FF: Plintossolo Pétrico; LA 2-5: Latossolo Amarelo distrófico textura média-argilosa; PA 2-5 PL: Argissolo Amarelo distrófico textura média-argilosa com plintita; LA 1-4: Latossolo Amarelo álico textura argilosa; LA 2-5-3: Latossolo Amarelo distrófico textura média-argilosa concrecionário; FFc: Plintossolo Pétrico concrecionário; LA 1-5-2: Latossolo Amarelo distrófico textura argilosa endoconcrecionário; LA 1-5: Latossolo Amarelo distrófico textura argilosa; LA 1-6: Latossolo Amarelo eutrófico textura argilosa.

Tabela 3. Estatística descritiva da elevação e declividade nas amostras circulares

\begin{tabular}{|c|c|c|c|c|c|c|c|c|}
\hline \multirow{2}{*}{ Amostra circular (1) } & \multicolumn{4}{|c|}{ Elevação (m) } & \multicolumn{4}{|c|}{ Declividade (\%) } \\
\hline & Mínimo & Máximo & Média & Desvio-padrão & Mínimo & Máximo & Média & Desvio-padrão \\
\hline 1 & 27,0 & 50,0 & 39,0 & 3,8 & 0,0 & 4,8 & 1,2 & 0,9 \\
\hline 2 & 34,0 & 50,0 & 43,8 & 3,0 & 0,0 & 2,6 & 1,0 & 0,6 \\
\hline 3 & 31,0 & 57,0 & 43,9 & 3,4 & 0,0 & 7,8 & 1,4 & 1,2 \\
\hline 4 & 32,0 & 43,0 & 38,0 & 1,7 & 0,0 & 3,3 & 0,8 & 0,5 \\
\hline 5 & 3,0 & 41,0 & 18,6 & 10,2 & 0,2 & 6,9 & 3,1 & 1,6 \\
\hline 6 & 8,0 & 36,0 & 22,4 & 6,6 & 0,0 & 8,4 & 3,0 & 1,4 \\
\hline 7 & 7,0 & 51,0 & 28,9 & 11,1 & 0,2 & 11,1 & 4,6 & 2,1 \\
\hline 8 & 25,0 & 65,0 & 44,8 & 9,8 & 0,4 & 10,6 & 4,5 & 2,2 \\
\hline 9 & 29,0 & 58,0 & 46,1 & 6,0 & 0,0 & 7,8 & 2,4 & 1,3 \\
\hline 10 & 13,0 & 43,0 & 28,3 & 6,4 & 0,3 & 10,0 & 3,2 & 1,7 \\
\hline 11 & 48,0 & 75,0 & 67,7 & 5,4 & 0,0 & 7,2 & 2,3 & 1,6 \\
\hline 12 & 34,0 & 75,0 & 58,0 & 11,1 & 0,2 & 11,9 & 3,8 & 2,3 \\
\hline 13 & 25,0 & 68,0 & 42,2 & 9,1 & 0,2 & 11,6 & 4,5 & 2,3 \\
\hline 14 & 11,0 & 52,0 & 28,5 & 9,9 & 0,0 & 13,0 & 4,8 & 2,9 \\
\hline 15 & 15,0 & 49,0 & 31,8 & 7,5 & 0,0 & 11,9 & 4,2 & 2,3 \\
\hline
\end{tabular}

(1) Vide solos ocorrentes no rodapé da tabela 2.
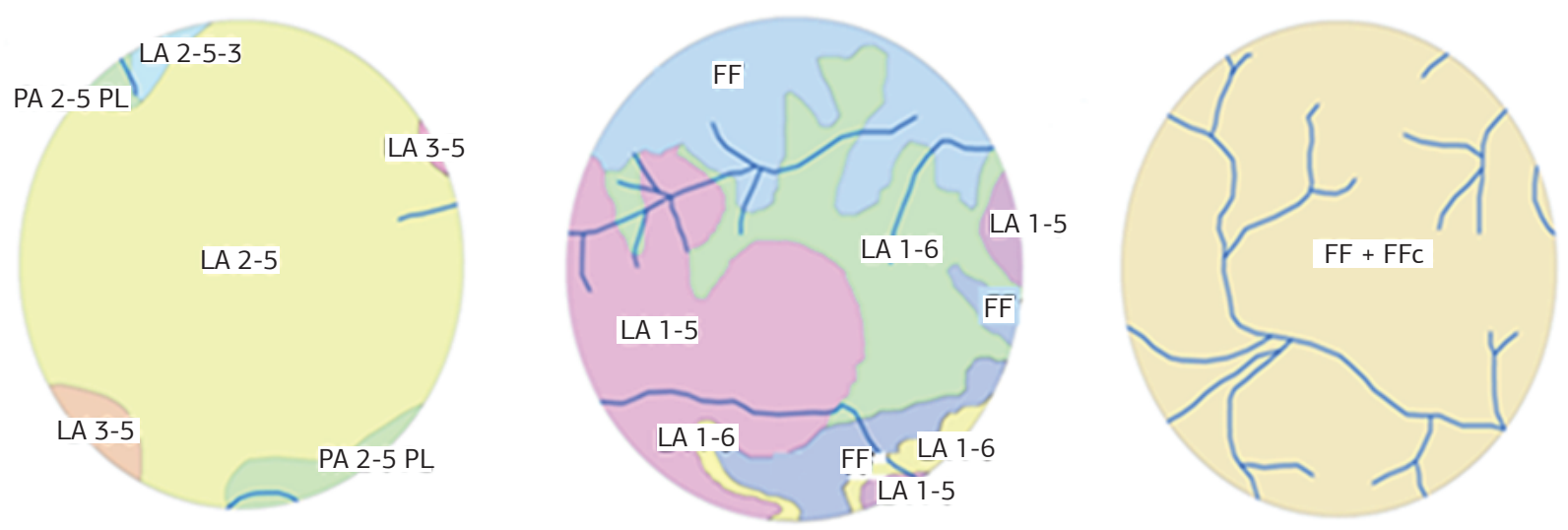

Figura 2. Exemplos de amostras circulares utilizadas para o cálculo da densidade de drenagem. Da esquerda para a direita: amostras 1,9 e 15. 

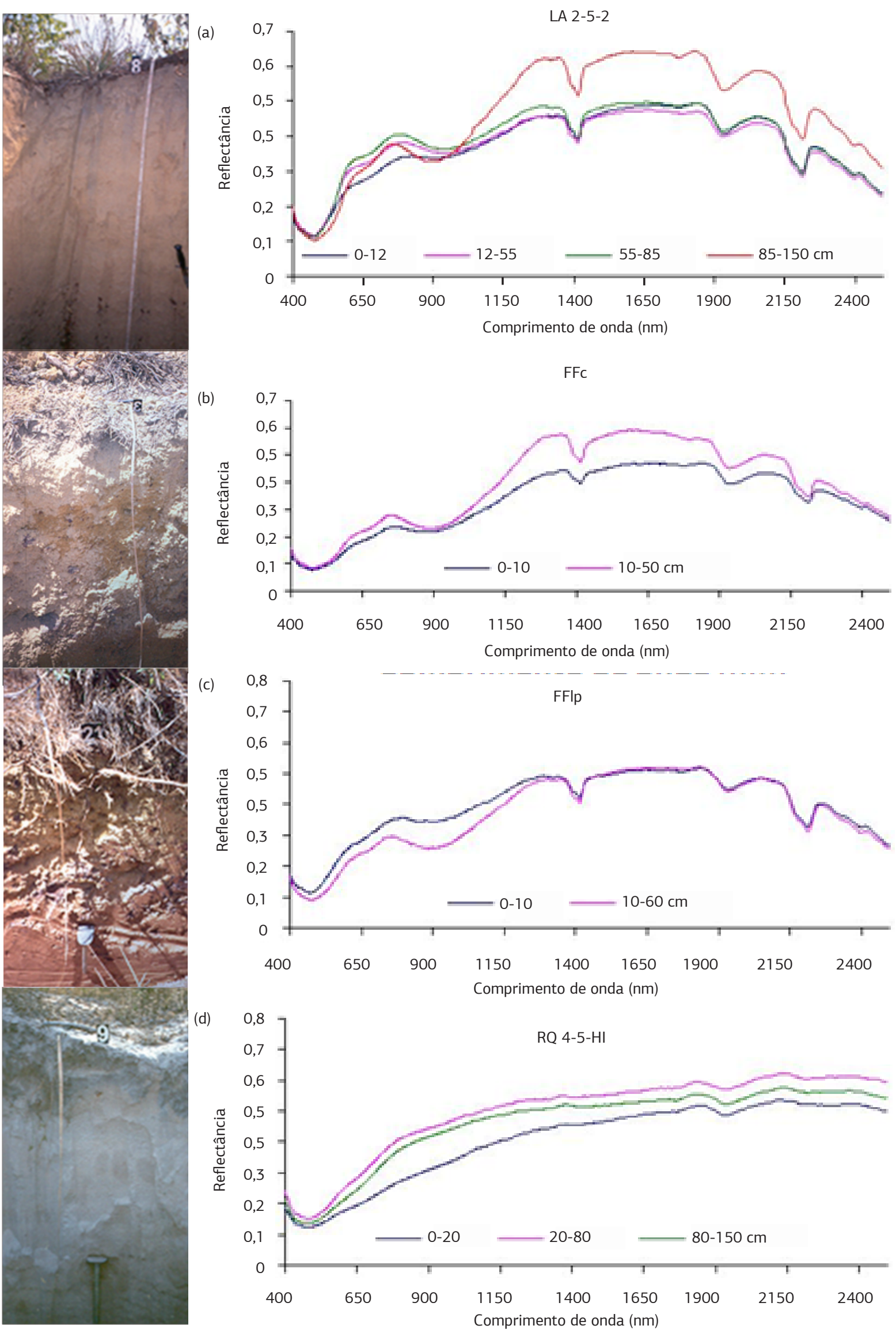

Figura 3. Perfil do solo e respectiva curva de reflectância espectral de: (a) Latossolo Amarelo distrófico textura média-argilosa endoconcrecionário (LA 2-5-2); (b) Plintossolo Pétrico concrecionário (FFc); (c) Plintossolo Pétrico litoplíntico (FFlp); e (d) Neossolo Quartzarênico distrófico com hidromorfismo (RQ 4-5-HI). 
enquadra nos tipos de curva apresentados em STONER e BAUMgardNER (1981).

\section{CONCLUSÃO}

As informaçôes quantitativas e qualitativas do relevo são eficazes na caracterização e discriminação dos solos estudados. A utilização de fotografias aéreas e imagem de radar permite a visualização espacial dos padróes de drenagem associados aos solos desenvolvidos do Grupo Barreiras. Recomenda-se, para regiôes com altos índices de precipitaçáo pluvial e nebulosidade, a utilização de imagens de radar.

A avaliação por espectrorradiometria de visível e infravermelho permite a caracterização individual das classes de solo, enquanto as fotografias aéreas e imagem de radar auxiliam na identificação dos padróes de ocorrência das diferentes classes de solo e, portanto, na delimitação das unidades de mapeamento.

As curvas espectrais de solos desenvolvidos do Grupo Barreiras, especialmente aquelas de horizontes concrecionários, são distintas das curvas representadas em outros trabalhos no Brasil e no exterior. Em suma, a aplicação de geotecnologias em conjunto com espectrorradiometria de visível e infravermelho contribui para a caracterização e discriminaçáo dos solos do Grupo Barreiras no Estado do Amapá.

\section{REFERÊNCIAS}

CAMARGO, A.O.; MONIZ, A.C.; VALADARES, J.M. Métodos de análise química, mineralógica e física de solos do IAC. Campinas: Instituto Agronômico de Campinas, 1986. 94p. (Boletim Técnico, 106)

CAMPOS, R.C.; DEMATTÊ, J.A.M. Cor do solo: uma abordagem da forma convencional de obtençấo em oposição à automatizaçáo do método para fins de classificaçáo de solos. Revista Brasileira de Ciência do Solo, v.28, p.853-863, 2004.

DEMATTÊ, J.A.M. Characterization and discrimination of soils by their reflected electromagnetic energy. Pesquisa Agropecuária Brasileira, v.37, p.1445-1458, 2002.
DEMATTÊ, J.A.M.; GARCIA, G.J. Alteration of soil properties through a weathering sequence as evaluated by spectral reflectance. Soil Science Society American Journal, v.63, p.327-342, 1999.

DEMATTÊ, J.A.M.; CAMPOS, R.C.; ALVES, M.C.; FIORIO, P.R.; NANNI, M.R. Visible-NIR reflectance: a new approach on soil evaluation. Geoderma, v.121, p.95-112, 2004.

EMBRAPA (EMPRESA BRASILEIRA DE PESQUISA AGROPECUÁRIA). CENTRO NACIONAL DE PESQUISA DE SOLOS. Procedimentos normativos de levantamentos pedológicos. Brasília: Embrapa, 1995. 116p.

EMBRAPA (EMPRESA BRASILEIRA DE PESQUISA AGROPECUÁRIA). CENTRO NACIONAL DE PESQUISA DE SOLOS. Sistema Brasileiro de Classificação de Solos. 2.ed. Rio de Janeiro: Embrapa Solos, 2006. 306p.

FORMAGGIO, A.R.; EPIPHANIO, J.C.N.; VALERIANO, M.M.; OLIVEIRA, J.B. Comportamento espectral (450-2.450 $\mathrm{nm})$ de solos tropicais de São Paulo. Revista Brasileira de Ciência do Solo, v.20, p.467-474, 1996.

FRANÇA, G.V.; DEMATTÊ, J.A.M. Parâmetros da rede de drenagem de solos da região de Iracemápolis (SP). Anais da Escola Superior de Agricultura Luiz de Queiroz, v.47, p.541-555, 1990.

LUEDER, D.R. Aerial photographic interpretation: principles and applications. New York: McGraw-Hill, 1959. 462p.

MADEIRA NETTO, J.S. Spectral reflectance properties of soils. Photo Interpretation, v.34, p.59-70, 1996.

RADAM. Projeto Levantamento dos Recursos Naturais: Amapá. Rio de Janeiro: Ministério das Minas e Energia, 1974. v.6.

RAIJ, B.V.; QUAGGIO, J.A.; CANTARELLA, H.; FERREIRA, M.E.; LOPES, A.S.; BATAGLIA, C.O. Análise química do solo para fins de fertilidade. Campinas: Fundação Cargill, 1987. 170p.

RANZANI, G. Manual de levantamento de solos. 2.ed. São Paulo: EDUSP, 1969. 167p.

SANTOS, D.S; LEMOS, R.C.; SANTOS, H.G.; KER, J.C.; ANJOS, L.H.C. Manual de descrição e coleta de solo no campo. 5.ed. Viçosa: Sociedade Brasileira de Ciência do Solo, 2005. 92p.

STONER, E.R.; BAUMGARDNER, M.F. Characteristic variations in reflectance of surface soils. Soil Science Society of America Journal, v.45, p.1161-1165, 1981. 